\title{
DESAFIOS DO ENVELHECIMENTO E A PARTICIPAÇÃO NA UNIVERSIDADE ABERTA À TERCEIRA IDADE: PERCEPÇÃO DE IDOSOS
}

\section{CHALLENGES OF AGING AND THE PARTICIPATION IN THE OPEN UNIVERSITY FOR THE SENIORS: PERCEPTION OF THE ELDERLY}

\section{DESAFÍOS DEL ENVEJECIMIENTO Y LA PARTICIPACIÓN EN LA UNIVERSIDAD ABIERTA DE LA TERCERA EDAD: PERCEPCIÓN DE LOS ANCIANOS}

\author{
Juliana Araújo Castilho' \\ Maria Olívia Sobral Fraga de Medeiros ${ }^{2}$ \\ Jacilene Santiago do Nascimento Trindade dos Santos ${ }^{3}$ \\ Juliana Bezerra do Amaral ${ }^{4}$ \\ Rudval Souza da Silva
}

Como citar este artigo: Castilho JA, Medeiros MOSF, Santos JSNT, Amaral JB, Silva RS. Desafios do envelhecimento e a participação na Universidade Aberta à Terceira Idade: percepção de idosos. Rev baiana enferm. 2020;34:e34846.

Objetivo: analisar a percepção do idoso acerca dos desafios do envelhecimento e de sua participação na Universidade Aberta à Terceira Idade. Método: pesquisa de natureza exploratório-descritiva com abordagem qualitativa, realizada com idosos participantes da Universidade Aberta à Terceira Idade de uma capital brasileira. Os dados foram coletados por meio de entrevista semiestruturada de setembro a outubro de 2016 e analisados por meio da Técnica de Análise de Conteúdo Temática. Resultados: emergiram três categorias temáticas: "envelhecimento: conquista, liberdade, oportunidade e etapa do ciclo da vida"; "o desafio de enfrentar as mudanças e o olhar da sociedade diante do envelhecimento" e "a Universidade Aberta à Terceira Idade como ferramenta para enfrentar os desafios do envelhecimento". Conclusão: a participação dos idosos no projeto Universidade Aberta à Terceira Idade é uma tática positiva para as inter-relações sociais e individuais, apresentando benefícios assertivos para a sua qualidade de vida.

Descritores: Enfermagem Geriátrica. Envelhecimento. Idoso. Educação. Universidade.

Objective: to analyze the perception of the elderly on the challenges of aging and of their participation in the Open University for the Seniors. Method: exploratory-descriptive study with qualitative approach, performed with elderly participants of the Open University for the Seniors in a Brazilian capital. The data were collected through semistructured interviews from September to October 2016 and analyzed using Thematic Content Analysis Technique. Results: three thematic categories emerged: "aging: conquest, freedom, opportunity and stage of the life cycle"; "the challenge to face the changes and society's view of aging" and "the Open University for the Seniors as a tool to face

\footnotetext{
Enfermeira. Pesquisadora Independente. Salvador, Bahia, Brasil. https://orcid.org/0000-0002-3706-0264.

Enfermeira. Especialista em Enfermagem em Cardiologia e Hematologia. Mestre em Enfermagem e Saúde. Professora Assistente da Escola Baiana de Medicina e Saúde Pública. Salvador, Bahia, Brasil. https://orcid.org/0000-000 I-68। I-378X.

Assistente Social. Especialista em Saúde Pública. Assistente Social da Universidade Federal da Bahia. Salvador, Bahia, Brasil. https://orcid.org/0000-000 I-9535-5565. 4 Enfermeira. Doutora em Enfermagem. Professora Adjunta da Universidade Federal da Bahia. Salvador, Bahia, Brasil. https://orcid.org/0000-0003-2355-9। I7.

Enfermeiro. Doutor em Enfermagem. Professor Adjunto da Universidade do Estado da Bahia e Professor Permanente do Programa de Pós-graduação em Enfermagem e Saúde na Universidade Federal da Bahia. Senhor do Bonfim, Bahia, Brasil. rudvalsouza@yahoo.com.br. https://orcid.org/0000-0002-7991-8804.
} 
the challenges of aging". Conclusion: the participation of the elderly in the project Open University for the Seniors is a positive tactic for the individual and social inter-relations, presenting benefits assertive for his/her quality of life.

Descriptors: Geriatric Nursing. Aging. Aged. Education. Universities.

Objetivo: analizar la percepción de los ancianos sobre los desafios del envejecimiento y de su participación en la Universidad Abierta de la Tercera Edad. Método: estudio de tipo exploratorio-descriptivo con abordaje cualitativa, realizado con ancianos participantes de la Universidad Abierta de la Tercera Edad de una capital brasileña. Los datos fueron recolectados por medio de entrevistas semiestructuradas de septiembre a octubre de 2016 y analizados por medio de la Técnica de Análisis de Contenido Temático. Resultados: emergieron tres categorias temáticas: "el envejecimiento: la conquista, la libertad, la oportunidad y la etapa del ciclo de la vida"; "el desafio de afrontar los cambios y la mirada de la sociedad delante el envejecimiento" y "la Universidad Abierta de la Tercera Edad como herramienta para enfrentar los desafíos del envejecimiento". Conclusión: la participación de los ancianos en el proyecto Universidad Abierta de la Tercera Edad es una táctica positiva para las inter-relaciones individuales y sociales, presentando beneficios asertivos para su calidad de vida.

Descriptores: Enfermería Geriátrica. Envejecimiento. Anciano. Educación. Universidades.

\section{Introdução}

No contexto atual, o crescimento do número de Universidades e Grupos de Convivência da Terceira Idade é acompanhado, sobretudo, pela capacidade de mobilizar pessoas idosas, promovendo a redefinição de valores, atitudes e comportamentos referentes aos novos sentidos que são atribuídos a esse estágio da vida, de modo que possam receber novo tratamento, como uma condição digna e justa, na busca por prazer e não mais como processo de perdas. O envelhecimento é um processo natural e dinâmico que atinge todos os seres humanos, ligados aos fatores biopsicossociais e espirituais ${ }^{(1)}$.

O envelhecimento social traz consigo mudanças nos papéis da pessoa idosa frente à família, ao trabalho e à sociedade, configurando, assim, um desafio real em virtude da necessidade de adaptação a essa nova realidade. Além disso, destaca-se que o processo de envelhecimento tem reflexos nas inter-relações entre a pessoa e seu contexto social, oriundas das experiências de vida, seja na formação, na educação, na construção social ou nas relações de trabalho. Tais inter-relações variam de indivíduo para indivíduo, sendo gradativas para uns e mais dinâmicas e aceleradas para outros. Essas variações, por sua vez, dependem de fatores como condições socioeconômicas, presença ou ausência de doenças crônicas e principalmente do estilo de vida de cada pessoa ${ }^{(1)}$. Desse modo, a pessoa idosa, ao vivenciar a aposentadoria, a percepção das mudanças corporais e a finitude, pode ter a sua autoestima prejudicada e isso pode afetar a sua relação consigo e com o outro e favorecer o isolamento social e a depressão ${ }^{(2)}$.

Neste contexto, e com a ampliação expressiva da população de pessoas idosas como fenômeno mundial, ações governamentais são requeridas para atender as particularidades desse perfil etário ${ }^{(3)}$. No Brasil, ferramentas sociais, como os Centros de Convivências e especificamente a Universidade Aberta à Terceira Idade (UATI), são espaços destinados à valorização e à participação ativa dos idosos, estando de acordo com as políticas públicas.

A pessoa idosa, segundo a Lei n. 10.741, de $1^{\circ}$ de outubro de 2003, que dispõe sobre o Estatuto do Idoso, tem direito à educação, cultura, esporte, lazer, diversões, acesso diferenciado a espetáculos, produtos e serviços que respeitem sua peculiar condição de idade cronológica. Além desses direitos, assegura a oferta de cursos e programas de extensão na modalidade de atividades formais e não formais, devendo o ente público proporcionar condições que visem o seu apoio na criação e no desenvolvimento das Universidades Abertas direcionadas à população de pessoas idosas ${ }^{(4)}$. 
Dessa forma, não se pode negar que a UATI tem um compromisso de intensificar ações que visam valorizar o conhecimento dos idosos e, assim, possibilitar o desenvolvimento de competências e habilidades que respeitem as experiências de vida dessas pessoas, em especial a diversidade de conhecimentos e ideias.

Os programas educacionais, sociais e de saúde planejados pelos docentes da UATI para os idosos têm por finalidade promover um envelhecimento equilibrado e bem-sucedido, de modo que os declínios peculiares à própria idade possam contrapor-se aos benefícios obtidos pela participação nas atividades ofertadas nesse espaço de convivência e troca de experiências. A proposta é de uma educação voltada para o enfrentamento dos desafios do envelhecimento, de maneira tal que o idoso possa vencer as adversidades impostas pela idade, adquirir conhecimentos e habilidades e ampliar os laços sociais ${ }^{(5)}$.

Tal contextualização permite inferir que o espaço da UATI apresenta características de um programa de atividades interativas, ofertado sem custos para os usuários e com a finalidade de ser um centro de ensino, estudos e assistência voltado para as questões do envelhecimento da população. Este fato justifica o desenvolvimento de estudos que possam dar visibilidade a um programa de tamanha magnitude.

Considerando as atividades de extensão realizadas em parceria entre docentes e estudantes do curso de graduação em enfermagem com a UATI de uma universidade pública de uma cidade do estado da Bahia, surgiu a seguinte questão: Qual a percepção do idoso quanto aos desafios do envelhecimento e a sua participação na Universidade Aberta à Terceira Idade?

O objetivo deste estudo é analisar a percepção do idoso acerca dos desafios do envelhecimento e sua participação na Universidade Aberta à Terceira Idade.

\section{Método}

Trata-se de um estudo exploratório e descritivo, com abordagem qualitativa, realizado em um programa de extensão universitária que desenvolve atividades da Universidade Aberta à Terceira Idade (UATI) na cidade de Salvador, Bahia, Brasil.

A pesquisa foi desenvolvida após apreciação e aprovação do projeto de pesquisa pelo Comitê de Ética e Pesquisa (CEP) da Escola Bahiana de Medicina e Saúde Pública sob Parecer n. 1.703.006 e atendeu às normas de pesquisa envolvendo seres humanos, conforme a Resolução n. 466/2012 do Conselho Nacional de Saúde. Todos os participantes foram esclarecidos sobre o estudo e assinaram o Termo de Consentimento Livre e Esclarecido (TCLE), sendo informados sobre as medidas para assegurar o anonimato e a confidencialidade sobre a origem dos dados obtidos.

A coleta de dados ocorreu entre os meses de setembro e outubro de 2016, durante as atividades desenvolvidas na UATI. A seleção dos participantes foi feita por meio da lista de matriculados em um componente curricular ofertado, que contava com 55 idosos. Foi adotado como critério de inclusão, estar frequentando a UATI e estar devidamente matriculado no componente "Identidade e Memória". Como critério de exclusão estabeleceu-se ter frequência esporádica nas atividades da UATI.

Todos os idosos foram convidados a participar da pesquisa e as entrevistas foram encerradas, tomando-se por base o critério de saturação dos dados, na décima terceira entrevista. A delimitação do número de entrevistados ocorreu quando o conteúdo foi suficiente para permitir o aprofundamento, a abrangência e a diversidade do processo de compreensão do grupo social estudado ${ }^{(6)}$. A entrevista semiestruturada contou com questões subjetivas que buscaram atender ao objetivo do estudo: Para o Sr(a). o que é envelhecer? Quais são os desafios do envelhecimento? Como era sua vida antes e após sua participação na UATI?

As entrevistas tiveram duração média de 15 minutos e foram gravadas, após autorização dos participantes, com o intuito de se assimilar de forma ampliada as contribuições. À medida que os participantes eram entrevistados, fazia-se 
a transcrição das falas, até não serem observadas diferentes concepções que pudessem acrescentar novas inferências, a ponto de permitir inovações nas unidades de registro. Após todo o processo de organização das falas, ocorreu o agrupamento de informações sobre a percepção do idoso acerca dos desafios do envelhecimento e a busca pelas contribuições que a UATI possibilitou-lhe. Os participantes foram identificados com a letra "I", seguida de um número cardinal, relativo à ordem de ocorrência da entrevista, com o propósito de preservar o anonimato.

Como técnica para análise, utilizou-se a Análise de Conteúdo Temática ${ }^{(7)}$, que se desdobra nas etapas de pré-análise, quando foi feita a leitura flutuante e a preparação dos dados, permitindo aos pesquisadores um envolvimento nas relações e impressões a respeito do conteúdo das entrevistas; a etapa seguinte, da exploração do material, permitiu a compreensão acerca das interseções e indicações relacionadas às falas. Destas, foram realizados recortes em unidades de significado, por meio de análise e seleção dos fragmentos das entrevistas que expressavam a percepção do idoso acerca dos desafios do envelhecimento e de sua participação na UATI. Após a identificação, as unidades de significado foram reunidas ordenadamente, para possibilitar a representatividade, abrangência e diversidade no processo de compreensão do objeto em estudo. A última etapa, a da inferência, possibilitou o tratamento e a interpretação dos resultados.

Após a análise, emergiram três categorias temáticas, a saber: Envelhecimento: conquista, liberdade, oportunidade e etapa do ciclo da vida; O desafio de enfrentar as mudanças e o olhar da sociedade diante do envelhecimento; A UATI como ferramenta para enfrentar os desafios do envelhecimento.

\section{Resultados}

Participaram do estudo 12 idosas e um idoso com idades compreendendo a faixa etária de 70 a 80 anos. Cinco das idosas tinham como profissão "professora", três "costureiras", uma "comerciária", uma "contadora", uma "secretária executiva" e uma "doméstica". O idoso informou como profissão ser "escritor/empresário do ramo de turismo". Todas informaram ser aposentadas, assim como o idoso. Quatro delas concluíram o "ensino fundamental completo"; uma, o "ensino médio completo"; quatro, o "ensino superior completo". Uma informou ter o "ensino fundamental incompleto" e as outras duas, o "ensino superior incompleto". O idoso informou ter "ensino superior completo". Quanto ao tempo de frequência na UATI, variou entre 2 e 17 anos. Em relação ao estado civil, três delas informaram ser solteiras, uma casada, cinco viúvas e três divorciadas, enquanto o idoso era divorciado.

As categorias que emergiram da análise explicam o fenômeno dos desafios do envelhecimento e a participação dos idosos na UATI.

Categoria 1-Envelhecimento: conquista, liberdade, oportunidade e etapa do ciclo da vida

Esta categoria expressa como as pessoas idosas perceberam o envelhecimento, enquanto etapa de vida carregada de conquistas, perdas, liberdade, oportunidades, aprendizagem intimamente ligada à ressignificação, à busca de conhecimento e de novas atividades. É uma experiência de vida. Eu me sinto numa idade boa.
Eu acho bom, eu acho ótimo ser idosa! (I-1).

Eu acho que é um dom que Deus dá a algumas pessoas. Minha família toda é de idosos, 60 e tantos, 70 e tantos. Minha mãe e meu pai morreram com 85. (I-2).

Eu estou na melhor fase da minha vida. Na minha velhice, para mim, foi tudo de bom. (I-5).

Envelhecer é viver de bem com a vida, né? Porque você procura, como eu e outras colegas, procuramos estudar, né?(I-6).

É passar a vida toda da gente, criar filhos, depois [...] eu acho ótimo, porque dá nova vida para a gente. Eu acho que eu, no envelhecimento, eu melhorei muito do que eu era mais jovem. (I-8).

Gosto de ser o que sou agora, porque tenbo liberdade. Não peço consentimento de ninguém, apenas comunico. Porque, graças a Deus, estou com essa idade, mas completamente lúcida, dirijo, entendeu? Eu esperava ser horrivel; para mim agora se transformou, porque eu aceitei! (I-10).

Agora estou com minha vida bem mais pautada. Estou bem mais com a vida controlada, tenho programação [UATI], tenho mais o direito de escolher aonde ir. É ter certas perdas, mas, ao mesmo tempo, é ter ganbos! Eu acho que estou tendo uma qualidade de vida. (I-12). 
Tudo aquilo que nasce, um dia envelhece... é normal. Agora, é saber envelhecer... 'Cê' pode envelhecer tendo uma saúde, como se diz assim, quase perfeita né? Porque não existe perfeita, uma saúde sadia, que você pode viajar, passear etc. e tal... ou envelhecer doente, que se chama de velho, né? Hoje, na psicologia e identidade e memória, não chama nem velho, chama de idoso, pode ter o idoso jovem... no caso eu. Eu declamo, canto, eu palestro, eu poso para fotografia. (I-13).

Outras unidades de significação ilustraram ainda o envelhecimento, tão somente como uma parte do ciclo da vida acompanhada pela perda de funcionalidades advindas das mudanças corporais seguidas de uma condição de fragilidade, sendo aceito como única opção.

É passar o tempo, né? A gente nasce, e vai passando os tempos e vai envelhecendo. (I-3).

Vem a idade madura e depois o envelhecimento. Para mim, é isso! Envelhecer, que eu saiba, é isso. Uma fase da vida. (I-4)

Eu acho que envelhecer é a gente aceitar os limites da idade! (I-7)

É a diminuição da vida, das nossas atividades, diminuição, inclusive, das nossas células. Nosso organismo vai perdendo a vitalidade. (I-9).

\section{Categoria 2-O desafio de enfrentar as mudanças e o olhar da sociedade diante do envelhecimento}

Nesta categoria, as unidades de contexto revelaram que os desafios enfrentados pelo envelhecimento estavam relacionados com o adoecimento, a redução da mobilidade e a presença de sintomas crônicos advindos de patologias, além da busca por manter as atividades físicas, domésticas, do cuidado ao outro, bem como de lazer.

Com 74 anos, faço fisica, faço dança de salão, faço faculdade [UATI], tomo conta de casa, ainda lavo, passo, cozinho, tomo conta de neto, filhos e tudo, e ainda tenho [tempo] para cuidar de mim. (I-5).

Restrição de nossos músculos, nossos membros. Eu tenbo que levantar, eu tenho que desafiar, isso é um desafio!(I-6).

Coisa que me incomoda realmente no envelbecer é que a gente vai tendo as dificuldades nos movimentos, as dores, as doenças que aparecem. E a gente tem que se adaptar e viver com elas. (I-9).

Vai aparecendo muitas dores, certo? E tem que lidar com tudo isso. Isso aí eu acho que é difícil. Analisando por este lado, é desafiador! (I-10).

Eu tenho algumas restrições, bipertensão, e estou fazendo tratamento aí, porque eu estou caindo muito, estou tendo muito problema com queda. Meus exames todos dão normais. Então, é o meu desafio com a velhice, graças a Deus! Porque quantas pessoas, quando chegam nos 60, já nem andam mais, né? (I-11).

Os resultados evidenciaram o desafio enfrentado por essas pessoas, frente ao estigma de ser idoso em uma sociedade preocupada com a estética e com padrões pré-estabelecidos que ceifam a autonomia e desconsideram as conquistas alcançadas com o envelhecimento. As manifestações de terceiros, que consideram as pessoas mais velhas incapazes, improdutivas, quase um estorvo para a sociedade, emergiram, por estarem fortemente presentes no cotidiano da vida das pessoas idosas, provocando, portanto, isolamento social e sofrimento mental. Ademais, estar na universidade foi também considerado desafiador, devido à visão desinformada, restrita e limitante da sociedade.

É um desafio vir aqui para a UATI, porque eu vim para aqui pela dor. Foi quando meu filbo faleceu. (I-4).

Existem as diferenças né, o tratamento das pessoas para com a gente. Esse negócio de senhora, a gente sente, né. Ou você se joga como nós, ou você fica recuada lá, fica abandonada da sociedade, a sociedade não te conbece! Isso é um desafio. (I-6).

É você aceitar o que os outros acham sobre você. Quando diz você está velho, por exemplo, você acha que você está bem, que está ótima na sua idade, mas uma pessoa vem de lá e dizer assim "você não é mais para fazer isso não, que você não tem mais idade para isso..." Isso é um desafio! Aí você tem que mostrar que você tem condições de fazer aquilo. (I-7).

A gente tem que se fazer aceitar, tem que se atualizar sempre, tem que aceitar muita coisa que dentro da idade, do padrão, eu não gostaria de aceitar, mas tenho que aceitar para sobreviver, para ser uma pessoa de novo. Porque, se não, a gente vai ser uma velha razinza, fora de moda. Eu procuro não ser uma velha ridicula muito avançada, mas sempre me mantendo num padrão aceitável. (I-12).

\section{Categoria 3-A UATI como ferramenta para enfrentar os desafios do envelhecimento}

A UATI era considerada pelas pessoas idosas um espaço de convivência que proporcionava melhora da qualidade de vida, por ser um ambiente de socialização, ocupação do tempo com atividades dinâmicas e interativas, promovendo bem-estar e autoestima. As pessoas idosas ressaltaram também como se sentiam acolhidas e 
motivadas, além de considerar o ambiente da UATI como extensão da sua família. Fica evidente, nas unidades de significação apresentadas a seguir, que a universidade é uma ferramenta promotora da saúde mental das pessoas idosas.

Teve uma grande mudança. Eu comecei a viver melhor, por causa dos contatos com os colegas. Você conbece outras pessoas, você se renova. Aqui é a minha família. Eu me sinto mais nova, mais jovem. Eu me sinto bem aqui dentro, viu? Eu amo! (I-1).

A minha alegria aqui aumentou. (I-2).

Eu vim para aqui pela dor [...] eu estava muito arrasada, muito deprimida, então uma criatura que foi daqui me trouxe. Então eu vim assim meio sem querer vir, mas depois eu achei que eu deveria ficar. Aqui tem colegas para conversar, professores bons. É isso, eu tô aqui esse tempo todo e estou me sentindo bem [...] aqui é minha segunda casa. (I-4).

Eu antigamente, eu não vivia, vegetava. Eu tinha uma vida muito agitada, trabalhava, tomava conta de filho. Depois que vim para cá eu me renovei. (I-5).

Você se sente acolhida, você faz parte daquilo que você tem vontade, você não fica inibida de chegar a qualquer lugar, de falar o que sente, de ser a pessoa que é. Incentiva demais! Eu faço tudo que um jovem faz, até mais! (I-6).

A UATI é também um espaço para aqueles que se preparam para viver a sua aposentadoria de modo dinâmico e num convívio social interativo. Para uma das idosas e para o idoso, houve uma preparação de vida para o envelhecimento e o espaço da universidade chegou como um complemento a esse processo, após todo um planejamento prévio.

Eu ingressei aqui logo depois da minha aposentadoria. Aqui me acrescenta muito. Você socializa, você faz amizades com gente da mesma faixa etária, que entende muita coisa que você já passou ou que poderá passar. É muito bom isso aqui! (I-10).

Bem, digamos que a UATI me ajudou entre 10 a 15\%, né? Que antes eu já tinha vida ativa. Trabalbei 34 anos com turismo, conbeci pessoas no mundo inteiro. Então, quer dizer, tudo que eu tenbo, que eu sei, digamos que 90\% quem me ensinou foi a convivência com o turismo no geral. (I-13).

\section{Discussão}

A forma como as pessoas idosas vivenciam seu próprio processo de envelhecimento sofre influência da interação entre os aspectos psicossociais, históricos, políticos, econômicos, geográficos e culturais, com ênfase nas diferenças relacionadas ao contexto diário de vida, suas crenças e particularidades pessoais, tornando cada idoso único. Assim, observa-se uma relação direta entre a concepção de velhice arraigada na sociedade em que o idoso está inserido e aquela construída pelo próprio idoso no seu processo de envelhecimento ${ }^{(8)}$.

O envelhecimento passa por um processo social e simultaneamente vital, carregado de múltiplas facetas geracionais num contexto social, político e individual. Tende a ocorrer direcionado por três diferentes níveis dimensionais: biológico, emocional e social ${ }^{(2,8)}$. O envelhecimento na dimensão biológica envolve diferentes alterações de ordem bioquímica/hormonal, bem como na anatomia e fisiologia peculiar ao processo de envelhecer. Essas mudanças são acompanhadas de uma gradativa debilidade das capacidades orgânicas. No que tange ao emocional, refere-se ao comportamento da pessoa em relação a si própria ou ao outro e está ligado às mudanças de atitude e limitações das capacidades. Quanto ao envelhecimento social, tem estreita relação com as normas morais de interação com a coletividade. A sociedade, com base no critério da idade, passa a controlar o comportamento em atividades específicas ou nas práticas de um agrupamento etário inserido na história ${ }^{(2)}$.

Tais modificações foram observadas nos resultados desta pesquisa, apresentados na primeira categoria. Estes convergem para as perspectivas de percepção de algumas idosas, perpassando pela oportunidade de ajustamentos às condições próprias do envelhecimento como parte do ciclo da vida, com perdas e ganhos para liberdade, independência, oportunidades de aprendizado, crescimento e novas conquistas. A autoimagem, reconhecida nas entrelinhas como decorrente das diretrizes do biológico, está completamente arraigada nas limitações impostas pela idade. Esse entendimento afasta-as dos significados, dos sentidos, das dimensões sensoriais e das experiências de vida.

A velhice impõe seus limites e precisa constituir-se em um papel social, uma temporalidade, um prestígio; precisa ser nominada e apresentar para a sociedade suas distintas particularidades. 
Todavia, o que se observa no cotidiano, são os preconceitos associados a quaisquer situações ou objetificações relacionadas ao envelhecer. Diversos termos e expressões têm sido atribuídos ao vocábulo velho, tais como: melhor idade, terceira idade, maduro, ancião, idoso, longevo, dentre tantos outros. Tais atribuições consideram que, na nossa sociedade ocidental, marcada por um capitalismo que supervaloriza a estética e o consumismo, ser velho é sinônimo de decadência e incapacidade física, psicológica e cognitiva, dependência, submissão e perda da autonomia ${ }^{(9)}$.

Há uma dimensão existencial no processo de envelhecimento que acaba por modificar toda a relação de vida da pessoa com seu tempo cronológico, além da relação desta com o mundo e sua própria história. Logo, um estudo ${ }^{(9)}$ mostrou que o envelhecer deve ser analisado de modo a ser considerado como uma manifestação de ordem biológica acompanhada de consequências psicológicas e cognitivas.

Ao considerar o tempo cronológico, destaca-se que este refere-se à possibilidade de se aproveitar os momentos, a possibilidade de estar aqui, de viver o presente. Assim, a vida pode ser vivida sem ter que seguir os ditames sociais impostos pela modernidade. Esta parece ser uma regra a ser cumprida por todos ${ }^{(9)}$.

Desse modo, pode ser observado que os resultados negativos do envelhecer direcionam seus esforços para as possibilidades quanto aos cuidados com a aparência, a estética, assim como para o autocontrole quanto aos fatores de risco para as vulnerabilidades às doenças próprias do processo fisiológico do envelhecimento. Nessa perspectiva, é possível um novo olhar para a velhice, como um fenômeno heterogêneo, no qual eventos como o declínio físico e cognitivo e o processo de adoecimento são vivenciados de modos diferentes pelos indivíduos ${ }^{(10)}$. Assim, as unidades de contexto resultantes desta pesquisa apontaram para tal percepção, ao evidenciar que a UATI possibilita o compartilhamento dessas vivências e, assim, viabiliza a essas pessoas idosas darem um novo sentido às suas vidas.

Quanto àquelas idosas que reconhecem as oportunidades de crescimento, vale destacar a peculiaridade de terem um senso de ajustamento psicológico aguçado que lhes permite desenvolver o seu poder de resiliência. Esta é vislumbrada por um processo de autoconhecimento e aceitação, que possibilita uma condição e favorece menor conflito quanto à aceitação das repercussões deletérias das vulnerabilidades esperadas frente ao envelhecimento. Além disso, propicia manejo, resistência e recuperação dos efeitos estressores negativos, por meio do uso de estratégias de ordem pessoal que podem ser caracterizadas por um estado de vida saudável, ativo, funcional, otimista e carregado de significados, boa autoestima, afetos positivos, propósitos de vida e autocontrole no gerenciamento das vicissitudes próprias da velhice ${ }^{(11)}$.

É importante integrar tais estratégias de enfrentamento com os recursos sociais, a exemplo de participação ativa na comunidade, implicando-se nas discussões sociais e tomadas de decisões, manutenção de um papel ativo na sociedade e uso de recursos que possibilitem a interação e a relação com a coletividade, a exemplo da participação em programas como a UATI.

Destaca-se que a negação da própria velhice mobiliza a onipotência e ofusca a percepção de que envelhecer pode ser também uma possibilidade de existência. Com frequência, as pessoas idosas dizem que "a velhice é muito feia". Essa imagem repulsiva é apreendida como o avesso da imagem ideal. Assim, quando o ideal fracassa, revela-se a "feiura". Um dos preconceitos que mais prevalece é a questão da velhice ligada à passividade; os velhos teriam pouca disponibilidade emocional e pouca capacidade para aprender ${ }^{(12)}$.

Os resultados deste estudo remetem a uma contextualização, ao nos permitir compreender que o envelhecer pode estar associado a uma fase boa da vida, à busca pela independência/autonomia, ainda que esteja associado ao declínio das capacidades do organismo, o que fisiologicamente é analógico à natureza humana. Há uma ressignificação, por meio de adaptações que alguns autores titulam como envelhecimento psicológico, que tem como consequência a ocorrência de readaptações, inadaptações e reajustamentos ${ }^{(13)}$. 
A segunda categoria remete aos desafios para enfrentar as mudanças e o olhar da sociedade diante do envelhecimento. Ficou evidenciado que existe uma divergência interpretativa no que tange à percepção do envelhecimento como uma capacidade de crescimento pessoal, mas também como apenas uma aceitação dos limites sociais e fisiológicos peculiares à senectude. A preocupação maior não é com a estética, mas com a perda de autonomia e independência, sendo crucial ressaltar o quanto é fundamental promover a inserção do idoso no contexto social ativo e dinâmico, permitindo-lhe trabalhar as limitações, a necessidade de conservar a independência e a autonomia.

Para compreender essa categoria, é importante definir o "envelhecimento ativo", entendendo-o como uma possibilidade de potencializar melhor estado de saúde diante das mudanças esperadas do envelhecer; assegurar a participação dinâmica no contexto social, em prol da qualidade de vida. Importante sinalizar que o vocábulo "ativo" deve ser compreendido como um processo dinâmico de participação da pessoa idosa nas discussões e tomadas de decisões nas questões de cunho social, cultural, econômico e espiritual. Nessas circunstâncias, ela pode discutir e tomar partido na defesa de suas ideias, em conformidade com suas histórias de vida e rica bagagem de conhecimento. Com isso, evita-se o entendimento errôneo de que o termo "ativo" restringe-se às atividades físicas ou de labor, remunerado ou não ${ }^{(14)}$.

Manter-se ativo ao longo da vida vem favorecer ganhos tanto para a saúde na dimensão biológica quanto na emocional e social, proporcionando qualidade de vida para a pessoa idosa. Assim, o planejamento estratégico para um envelhecimento ativo deve ser baseado nos direitos da pessoa idosa. Deve permitir o reconhecimento quanto à paridade de oportunidades e também respeitar a maneira de cada pessoa idosa lidar com os aspectos peculiares da sua história de vida. É preciso evitar manter o foco nas necessidades vislumbradas por uma visão depreciativa de que a pessoa idosa é um ser passivo e sem autonomia. Assim, será possível respeitá-la e apoiar as suas responsabilidades no exercício de sua autonomia e participação nos processos decisórios, bem como naqueles inerentes aos aspectos da vida em sociedade ${ }^{(8)}$.

As demandas sociais e econômicas aumentaram à medida que o envelhecimento global atingiu o século XXI. Esse processo tem acarretado grandes desafios, a exemplo daqueles relacionados às questões econômicas, sociais e culturais que envolvem a participação da pessoa, da família e da comunidade numa perspectiva global. Esse cenário exige da sociedade novas competências e habilidades para lidar com as demandas decorrentes da evolução demográfica ${ }^{(3)}$.

Em se tratando de tais desafios, foi possível observar nesta pesquisa que existe uma percepção de que o envelhecer é uma provocação para além da subjetividade do ser, mas, principalmente, é ato desafiador para a manutenção de autonomia e independência na execução das atividades da vida diária.

Esta percepção, todavia, não é generalizável. Logo, cabe às sociedades capitalistas, diante do cenário de um processo de desigualdades sociais, desenvolver uma dinâmica de mobilidade social com um olhar direcionado para as distintas particularidades do envelhecimento saúde, corpo e longevidade -, com desafios para além dos grupos sociais. É indispensável ampliar as discussões, para que ultrapassem as questões de preconceitos quanto ao ageismo e alcancem as vertentes ligadas ao preconceito relacionado às camadas desassistidas e menos favorecidas economicamente $^{(10)}$.

Outro desafio identificado foi desvelado mediante a citação de estereótipos negativos à velhice nos aspectos físicos, cognitivos e estéticos e sua influência negativa na saúde mental e física do idoso. Tipificar o sujeito pela idade causa danos reais à saúde mental dos idosos, reduzindo sua vontade de viver. O problema torna-se mais difícil porque o preconceito e os estereótipos sobre o envelhecimento tendem a ser reconhecidos não como problemas sérios, mas como "verdades divertidas" e, assim, o ageísmo perpetua nas entrelinhas de nossa sociedade. Ele representa uma ameaça clara e direta ao envelhecimento saudável $^{(15)}$. 
Indivíduos que ressignificam e evitam tais definições negativas veem o envelhecimento como um tempo de crescimento contínuo, com positividade, socialização e atividade e tendem a mostrar resultados de saúde mental e física significativamente melhores do que seus pares com maior pessimismo ${ }^{(15)}$. As idosas e o idoso deste estudo perceberam na UATI uma forma de dar novos sentidos às suas vidas.

Nesse contexto, emergiram das unidades de significação as adaptações estéticas e corporais como um desafio que foi associado à beleza, como um costume contemporâneo influenciado pelos atuais padrões estéticos. A experiência estética de uma expressão revela uma dualidade entre as imagens apreciadas e depreciadas, que são expressas por diferentes formas de compreender e sentir a realidade da velhice. Ao desvelar a aparência do corpo envelhecido, as mulheres confessam seus sentimentos em relação às experiências dos anos vividos em um entrelaçamento de beleza e fealdade. É um olhar atento ao corpo e à alma, que segue regras, condutas e princípios. A percepção da beleza é abstraída na singularidade do ser pela apreciação e pelo amor dedicados a si mesmas. É por meio da linguagem que o corpo se apresenta como portador de significado ${ }^{(16)}$.

Sentir-se partícipe dessa realidade implica numa visão de jovialidade que requer atualização e atitude de ativismo profissional, social, intelectual e sexual. Assim, percebe-se que, diante dos ditames sociais e coercitivos, para assumir tais papéis, a pessoa idosa precisa abraçar seu potencial de exercer os micro poderes em cada espaço ocupado ${ }^{(17)}$. Estar inserido num programa como a UATI, é uma forma de colocar-se em tais dispositivos, resistindo às imposições sociais e colocando-se diante delas, demonstrando os seus posicionamentos.

Subjetivamente, observa-se um processo de identificação com essa visão, com o exercício da jovialidade, com a disposição para atualizar-se e aceitar as mudanças da sociedade, além da tentativa de manter-se ativo em diversas áreas. Em contrapartida, há pontos de resistência, como as crenças e a opção por determinadas atividades de lazer, em que os sujeitos deslizam e constituem-se mediante práticas consideradas mais tradicionais. Assim, configura-se a compreensão de que esses sujeitos estão transformando-se em velhos idosos, o que eles não se permitiram deixar de ser na sua totalidade ${ }^{(17)}$.

Dessa forma, os idosos precisam de incentivos e de meios para estruturarem o rompimento de barreiras pautadas nas adversidades sociais impostas pelo envelhecimento e investirem em espaços que fomentem a autoestima, a criatividade e o apoio biopsicossocial. As políticas e os programas vinculados a esse paradigma não refletem a realidade em sua totalidade, pois há uma parcela de idosos que permanece independente e participa ativamente da força de trabalho, especialmente nos países em desenvolvimento ${ }^{(8)}$.

Desse modo, almejando a manutenção de uma boa satisfação com a vida, programas voltados para a educação permanente para idosos, fornecidos por universidades e outras fontes, contribuem para a avaliação de sua própria trajetória de desenvolvimento e compromisso com a sociedade, além de considerar seu próprio compromisso de buscar um ideal de excelência pessoal ${ }^{(18)}$. Pode-se dizer que viver a experiência do envelhecimento como um momento privilegiado da vida também é algo que se aprende em um estabelecimento educacional.

No Brasil, há uma quantidade relevante de UATI, as quais tiveram influência de programas similares desenvolvidos na Europa, com origem na França, no final dos anos de 1960, que recebiam a designação de "Universidades de Tempo Livre". Estas têm por objetivo proporcionar atenção à população de pessoas idosas com vista a melhorar sua qualidade de vida. Têm desenvolvido intervenções psicoeducacionais para aprimorar saberes e capacidades, de modo a encorajar os idosos a sentirem-se aceitos e compreendidos em suas habilidades e aptidões, levando em consideração suas potencialidades, assim como suas dificuldades e limitações ${ }^{(19)}$.

Observou-se, neste estudo, que alguns idosos conseguiram voltar a investir em seus talentos e projetos não concluídos, devidamente adaptados ao momento atual da vida. Ao serem questionados sobre como era sua vida antes e depois da participação em uma UATI, objetivando 
compreender as repercussões do envelhecer de um idoso ativo, os entrevistados apontaram positivamente tal participação.

Compreende-se que é essencial reforçar os sensos de "negatividade", "realização" e "competência". Para isso, é necessário que o idoso envolva-se com novos projetos que possibilitem desenvolver suas habilidades e ajudem a transformar seus desejos latentes em ações que deem sentido a sua vida. Para tanto, é necessário o apoio das instituições governamentais, com políticas públicas que desenvolvam intervenções, possibilitando integrar a população de idosos ao contexto social e, assim, fortalecer a promoção do envelhecimento saudável ${ }^{(20)}$.

Com isso, é possível inferir que uma participação dinâmica em programas como a UATI representa novos desafios que podem contribuir para a contínua participação ativa da pessoa idosa, para tornar sua vida mais dinâmica e interativa.

A UATI é percebida como um centro de convivência contributivo ao convívio social para além de uma rede de apoio integral e singular. Assim, tem papel relevante e potencializa a participação ativa das pessoas idosas, além de favorecer a troca de experiências e o companheirismo entre aqueles que vivenciam a velhice.

Vale destacar os momentos vividos pelos idosos quanto às perdas, a exemplo da perda de companheiros, cônjuge ou amigos de longa data com os quais compartilhou a vida. São experiências dolorosas e difíceis, pois os aproximam da possibilidade iminente da morte, retomando o conflito entre a intimidade vivenciada e as situações de isolamento. Com isso, percebe-se que a convivência no programa é uma possibilidade de compartilhar tais experiências e ter o reconhecimento de que a história de vida de um pode também ser a de tantos outros, vislumbrando a realidade de que a morte é parte do ciclo da vida e necessitamos aprender a lidar com ela. A UATI proporciona essa oportunidade de criar vínculos e compartilhar saberes, além da construção de um novo senso de mutualidade e de convívio social, o que foi evidenciado nos resultados deste estudo, com base no que foi dito pelos idosos.

Outro ponto importante a ser discutido é o planejamento da vida pós-aposentadoria, haja vista a necessidade de reorganização no planejamento do tempo que passa a ser ocioso, devido a não mais desempenhar as atividades laborais. Isso requer do idoso um plano estratégico de novas experiências, sejam remuneradas ou não, para dar sentido a esse tempo que antes era preenchido com o trabalho assalariado.

Um estudo de revisão da literatura aponta que tal preparação para a aposentadoria é uma estratégia imprescindível para que se mantenha a qualidade de vida do idoso quando conclui seu ciclo de atividade laboral. Assim, a preparação para a aposentadoria deve ser uma prática nos ambientes de trabalho, de modo que as pessoas, quando se aproximarem da aposentadoria, possam reorganizar seus cotidianos sem o trabalho, dando sentido às suas vidas e sentindo-se úteis ${ }^{(21)}$.

Para aquele indivíduo que teve uma estrutura de suporte socioeconômico para a aposentadoria, o afastamento das atividades laborativas e a permanência num espaço em comum, como a UATI, que vislumbra a manutenção de inserção em atividades que envolvem dinâmicas sociocognitivas, além de atividades psicoeducativas com planejamento e desenvolvimento contínuo, possibilita estímulo e adesão, além da ressignificação das concepções equivocadas sobre a velhice, com repercussões positivas na sua vida.

Apontam-se como limitações do estudo, ter sido realizado em apenas uma unidade da UATI, bem como a dificuldade de comparação com outros estudos semelhantes, devido à escassez desses, o que permite sugerir-se investigações semelhantes, em outras realidades.

\section{Conclusão}

Os resultados demonstraram a existência do preconceito social marcante na vida da pessoa idosa, tornando o envelhecimento um processo com grandes desafios relacionados ao processo 
Juliana Araújo Castilho, Maria Olívia Sobral Fraga de Medeiros,

de adoecer, à redução da mobilidade, à presença de sintomas crônicos, à busca pela manutenção das atividades físicas e domésticas e ao cuidado do outro/familiares. Diante disso, os idosos buscavam estratégias para vencê-los, sendo a sua participação na UATI uma tática positiva e que conduzia a benefícios propícios a uma melhor qualidade de vida.

Compreender a multidimensionalidade do processo do envelhecimento, das esferas que integram os contextos sociais, econômicos, políticos, funcionais e clínicos, foi crucial para entender quem é o sujeito ao qual estamos nos reportando nos serviços de saúde e de educação. Entender o envelhecer e seus desafios sob a ótica da pessoa idosa tende a favorecer diretamente ao profissional de saúde, especialmente ao enfermeiro, para compreender a contextualização do universo que o engloba nos domínios da vida humana, na busca de bem-estar biopsicossocial.

Ademais, o estudo contribuiu com o protagonismo e a participação social desses idosos, considerando-os como sujeitos ativos. Espera-se fomentar reflexões quanto à atuação efetiva dos idosos na sociedade, o que pode ser considerado um dos maiores desafios enfrentados pela pessoa idosa, desvelados pelas falas dos participantes deste estudo.

\section{Colaborações:}

1 - concepção, projeto, análise e interpretação dos dados: Juliana Araújo Castilho, Maria Olívia Sobral Fraga de Medeiros e Rudval Souza da Silva;

2 - redação do artigo e revisão crítica relevante do conteúdo intelectual: Juliana Araújo Castilho, Maria Olívia Sobral Fraga de Medeiros, Jacilene Santiago do Nascimento Trindade dos Santos, Juliana Bezerra do Amaral e Rudval Souza da Silva;

3 - aprovação final da versão a ser publicada: Juliana Araújo Castilho, Maria Olívia Sobral Fraga de Medeiros, Jacilene Santiago do Nascimento Trindade dos Santos, Juliana Bezerra do Amaral e Rudval Souza da Silva.

\section{Referências}

1. Martinson M, Berridge C. Successful aging and its discontents: a systematic review of social gerontology literature. Gerontologist. 2015;55(1):58-69. DOI: 10.1093/geront/gnu037

2. Fundo de População das Nações Unidas. Envelhecimento no século XXI: celebração e desafio (Resumo Executivo) [Internet]. New York: Fundo de População das Nações Unidas; HelpAge International; 2012 [cited 2018 Jan 3]. Available from: https://www.unfpa.org/sites/default/files/ pub-pdf/Portuguese-Exec-Summary_0.pdf

3. Mesquita RAV, Costa NE, Carvalho HBC. Políticas públicas de saúde para o envelhecimento e a velhice. In: Freitas EV, Py L, organizadores. Tratado de Geriatria e Gerontologia. 3a ed. Rio de Janeiro: Guanabara Koogan; 2013. p. 2222-32.

4. Brasil. Lei n. 10.741, de $1^{\mathrm{o}}$ de outubro de 2003. Aprova o Estatuto do Idoso e dá outras providências [Internet]. Brasília (DF); 2003 [cited 2018 Feb 3]. Available from: http://www.planalto.gov.br/ ccivil_03/leis/2003/110.741.htm

5. Pereira AAS, Couto VVD, Scorsolini-Comin F. Motivações de idosos para participação no programa Universidade Aberta à Terceira Idade. Rev bras orientac prof. 2015 [cited 2018 Feb 3];16(2):207-17. Available from: http://pepsic. bvsalud.org/pdf/rbop/v16n2/11.pdf

6. Minayo MCS. Amostragem e saturação em pesquisa qualitativa: consensos e controvérsias. Rev Pesq Qualitativa [Internet]. 2017 [cited 2018 Feb 3];5(7):1-12. Available from: http://rpq.revista. sepq.org.br/index.php/rpq/article/view/82/59

7. Bardin L. Análise de conteúdo. 6a ed. Lisboa: Edições 70; 2016.

8. Faller JW, Teston EF, Marcon SS. A velhice na percepção de idosos de diferentes nacionalidades. Texto Contexto Enferm. 2015;24(1):28-37. DOI: https://doi.org/10.1590/0104-07072015002170013

9. Vilhena J, Novaes JV, Rosa CM. A sombra de um corpo que se anuncia: corpo, imagem e envelhecimento. Rev latinoam psicopatol fundam. 2014;17(2):251-64. DOI: https://doi.org/10.1590/19840381v17n2a08

10. Rebouças M, Matos MR, Ramos LR, Cecílio LCO. What's new about being old. Saude soc. 2013;22(4):1226-35. DOI: https://doi.org/10.1590/ S0104-12902013000400023 
11. Fontes AP, Neri AL. Resilience in aging: literature review. Ciênc saúde coletiva. 2015;20(5):1475-95. DOI: https://doi.org/10.1590/1413-81232015205.00502014

12. Teixeira SMO, Marinho FXS, Vasconcelos AMC, Martins JCO. Da velhice estigmatizada à dignidade na existência madura: novas perspectivas do envelhecer na contemporaneidade. Estud pesqui psicol [Internet]. 2016 [cited 2018Feb3]; 16(2):469-87. Available from: http://pepsic.bvsalud.org/pdf/ epp/v16n2/n16a10.pdf

13. Lara J, Cooper R, Nissan J, Gint AT, Khaw KT, Dear IJ, et al. A proposed panel of biomarkers of healthy ageing. BMC Med. 2015;13(222):1-8. DOI: 10.1186/s12916-015-0470-9

14. Rosa CM, Veras L, Assunção A. Reflexos do tempo: uma reflexão sobre o envelhecimento nos dias de hoje. Estud pesqui psicol [Internet]. 2015 [cited 2019 Oct 8];15(3):1027-44. Available from: http:// pepsic.bvsalud.org/pdf/epp/v15n3/v15n3a14.pdf

15. Nelson TD. Promoting healthy aging by confronting ageism. Am Psychol. 2016;71(4):276-82. DOI: $10.1037 / \mathrm{a} 0040221$

16. Fin TC, Portella MR, Scortegagna SA. Old age and physical beauty among elderly women: a conversation between women. Rev bras geriatr gerontol. 2017;20(1):74-84. DOI: https://doi. org/10.1590/1981-22562017020.150096

17. Bazza AB. A constituição da subjetividade no discurso do idoso sobre si. Ling (dis)curso.
2016;16(3):449-64. DOI: http://dx.doi.org/10.1590/ 1982-4017-160305-1416

18. Cachioni M, Delfino LL, Yassuda MS, Batistoni SST, Melo RC, Domingues MARC. Subjective and psychological well-being among elderly participants of a University of the Third Age. Rev bras geriatr gerontol. 2017;20(3):340-51.DOI: https://doi.org/10.1590/ 1981-22562017020.160179

19. Inouye K, Orlandi FS, Pavarini SCL, Pedrazzani ES. Impact of the Third Age Open University on the Quality of Life of the Elderly. Educ Pesqui. 2018;44:e142931. DOI: http://dx.doi.org/10.1590/ S1678-4634201708142931

20. Miranda GMD, Mendes ACG, Silva ALA. Population aging in Brazil: current and future social challenges and consequences. Rev bras geriatr gerontol. 2016;19(3):507-9. DOI: https:// doi.org/10.1590/1809-98232016019.150140

21. Both TL, Kujawa DR, Wobeto MI, Savaris V. Consideração sobre o idoso aposentado: uma intervenção da Terapia Cognitivo-Comportamental como instrumento de preparação à aposentadoria. Rev Bras Ciênc Envelhec Hum. 2012;9(1):90-101. DOI: $10.5335 /$ rbceh.2012.037

Recebido: 11 de dezembro de 2019

Aprovado: 10 de fevereiro de 2020

Publicado: 2 de abril de 2020

A Revista Baiana de Enfermagem utiliza a Licença Creative Commons - Atribuição-NãoComercial 4.0 Internacional.

https://creativecommons.org/licenses/by-nc/4.0/

Este artigo é de acesso aberto distribuído sob os termos da Licença Creative Commons (CC BY-NC).

Esta licença permite que outros remixem, adaptem e criem a partir do seu trabalho para fins não comerciais. Embora os novos trabalhos tenham de lhe atribuir o devido crédito e não possam ser usados para fins comerciais, os usuários não têm de licenciar esses trabalhos derivados sob os mesmos termos. 